CWIS

24,3

152

\title{
Changing paradigms: managed learning environments and Web 2.0
}

\author{
Emory M. Craig \\ The College of New Rochelle, New Rochelle, New York, USA
}

\begin{abstract}
Purpose - The purpose of this paper is to understand how emerging technologies and Web 2.0 services are transforming the structure of the web and their potential impact on managed learning environments (MLS) and learning content management systems (LCMS).

Design/methodology/approach - Innovative Web 2.0 applications are reviewed in the paper to explore how they incorporate a new paradigm, reshaping the web as an electronic platform for social networks, where users share, edit and collaborate on the publication of content.

Findings - The paper finds that, in this rapidly changing environment, educators need to consider the implications of these developments for the current design of the LCMS. An emerging generation of users influenced by social networking experiences and empowered to create, publish, appropriate and redistribute content may find the structures of the LCMS traditional and inflexible in contrast with the user-centered approach of Web 2.0 services. This fundamental shift in the experience of the digital environment in the social world will require innovative solutions, including broad institution-wide dialogues on the role of organizations in a Web 2.0 environment, innovative approaches to faculty training, a new emphasis on the role of faculty as learners in a rapidly changing environment, and rethinking the underlying architecture of the LCMS model.
\end{abstract}

Research limitations/implications - The recent emergence of these new developments and the essentially fluid nature of these innovations on the web suggest that the conclusions here remain essentially speculative in nature.

Originality/value - This paper identifies a critical challenge in the integration of technology into the teaching-learning environment and the re-evaluation of the role of a vendor-specific enterprise LCMS in the design of e-learning facilities.

Keywords Learning methods, Content management, World wide web

Paper type Viewpoint

\section{Introduction}

With the rapid evolution of technology over the past 15 years, managed learning environments (MLEs) have become essential components in the digital landscape of higher education. Beginning with simple web pages and generic content libraries, a variety of early initiatives including Stanford Online, "Web Course in a Box," and TopClass evolved during the middle of the previous decade. In 1997, the Oncourse Project at Indiana University would establish a framework of a "template-based course management system" that would be the basis of many of the later learning management systems (LMS) including WebCT and BlackBoard. Simultaneously, Bodington Virtual Learning Environment (VLE) developed at the University of Leeds, incorporated multiple roles for users to access resources and the flexibility to organize resources based student and faculty needs. The release of the EDUCOM/NLII Campus-Wide Information System Vol. 24 No. 3, 2007

pp. $152-161$

(C) Emerald Group Publishing Limited $1065-0741$

DOI 10.1108/10650740710762185 Instructional Management Systems Specifications Document Version 0.5 (April 29, 1998) brought about the standardization of many of these developments and 
encouraged the widespread use of an LMS to store and distribute academic resources and provide new tools for communication and collaboration.

These developments continued as higher education expanded access to new participants (lifelong learners), sought cost efficiencies across traditionally separate units and incorporated new modalities of assessment. The development of MLEs, driven largely by educators in Europe and Australia, has resulted in learning environments with a focus on collaboration, technical interoperability, and customizable learning experiences. Mature learning content management systems (LCMS) extend beyond the initial achievements of LMSs, incorporating collaboration tools, assessment and analytics, and compliance to accepted standards SCORM, AICC, PENS, IMS, etc). The current environment remains highly fluid as MOODLE and SAKAI move toward offering similar features through open-source projects and inter-institutional collaboration.

This brief synopsis of the development of MLEs and the integration of technology into the teaching-learning environment reveals the significant progress that has been made in the design of e-learning environments, despite the initial skepticism on the part of many faculty in the previous decade. The pace of change even within higher education still presents a challenge to many faculty and significant resources are devoted to training programs. But we should also be cautious in assuming our challenges reflect only a single line of technological development. The growth of a dynamic open-source movement, a wealth of innovative technology tools and the explosion of interest in social networking sites among a new generation of students suggests that our current LCMS model may be situated not at the center, but on the margins of a profound revolution in web-based applications. This transformation of the web through the introduction of user-centered publication and distribution tools is undermining the traditional paradigm of the user experience. An earlier content distribution pattern that modeled itself on a print publication paradigm is inverting itself as users become empowered to create, publish and distribute content, making them media producers instead of consumers. That this is not simply an enhancement of the web but a radical evolution of its basic structure, suggests that it may have profound implications for the integration of technology in our learning environments. As Ron Yanosky, research fellow for the Educause Center for Applied Research has argued, we may be "... on the threshold of a generational change in these systems" (Sausner, 2005).

Higher education, then, is confronting a dual challenge in the rate of acceptance of technology by some faculty and the rapid pace of innovation, which is creating a unique set of challenges. While this paper focuses on the latter, it is critical that we not ignore the fact that a substantial percentage of faculty remain skeptical of the value of technology in the learning process. In a survey of department chairpersons in the USA that asked if teaching had improved through the utilization of an LCMS, fully 51 percent said it had not made a significant difference (Harrington et al., 2004). However, the fundamental issue here may a conceptual one: if faculty utilize a more limited LMS only as a means of adapting conventional courses to an online environment, there will be little change from the standard lecture format of the traditional classroom experience (Reeves et al., 2004). As Acker (2004) has pointed out, the LMS is well suited for the electronic distribution of academic resources, but that can actually reinforce a transmission model of learning that fails to support a variety of different learning 
CWIS

24,3

154 styles. While we may hold faculty responsible for the failure to achieve effective communication and collaboration through an LMS, part of the issue may be the software's own failure to provide the appropriate learning tools.

In the following, I would like to examine the second of these issues, the implications of emerging technologies for our LCMS. Many of the reviews of Web 2.0 developments focus on description and analysis of the innovative tools increasingly at our disposal; but it is important to understand the way these technological developments reshape both the role and status of the user. As social networking transforms the experience of the individual and challenges the operating practices and structure of social organizations, it is hard to imagine that our LCMS will remain untouched by these developments. Indeed, change happens, but it is not always through progress and development of the entity, object or a process in question. A rapidly changing social environment may cast our LMCS in a profoundly different light, where a once innovative solution to e-learning design issues increasingly appears as a rigid and inflexible system predicated on an outdated mode of content creation and distribution. After examining the underlying dynamics of Web 2.0 developments and their implications for the LCMS model, we can briefly explore potentially innovative solutions to the challenges of elearning design in a radically new landscape.

\section{Web 2.0 and mashups}

To glance outside the confines of the academy is to see a social environment undergoing profound change through a tsunami-like flood of innovative tools and services that foster new modes of collaboration and social organization. The rapid evolution of blogs, wikis, social networking and bookmarking, and related applications offer rich user experiences where the process of knowing is a community-based, collaborative endeavor (Alexander, 2006). These tools and services are generally referred to as Web 2.0, a term first coined by Tim O'Reilly and Dan Doughtery at a conference brainstorming session in 2004. As O'Reilly (2005) points out, there is no “... hard boundary here, but a gravitational core" around which a number of "principles and practices" cohere. It is a concept that encompasses a diverse set of independent yet interlocking applications (relying on generally pre-existing technologies) that are transforming user experience. The first stage of the web, to the extent that it can be roughly demarcated by stages, was about navigating relatively static web sites and accessing content on a print-based publication model. In contrast, Web 2.0 developments undermine the traditional boundaries between central publishing sites and a passive audience by providing remotely supported platforms and data for users to undertake their own collaborative content creation and publication.

Many of these Web 2.0 technologies have been developed using AJAX or Asynchronous JavaScript and XML (Jesse James Garrett of Adaptive Path coined the term in February 2005), a web development technique that transfers the rendering of the user interface to a local machine while maintaining a significant portion of the data on a remote server to create a highly responsive desktop experience. While AJAX is not universally applicable to the broad range of developments in Web 2.0, it is an important tool in providing drag and drop functionality for page content positioning and simultaneous user editing by overcoming the need to fully reload a web page with every alteration. To provide one example, Writely (recently acquired by Google and now known as Google Docs) is a simple and secure AJAX-based online word 
processing program and collaboration platform that provides users with Word-like functionality. With desktop-like responsiveness, users cannot only create and store their own documents, but work synchronously to collaboratively create, edit and share content while maintaining revision histories. Like many applications built on AJAX, Google Docs was designed to integrate with other tools through the use of application programming interfaces (APIs) that are accessible to advanced end-users and can be utilized to create new applications.

To understand Web 2.0 is to see what Hinchcliffe (2006a) has referred to as the trinity of people, data, software, with the end user playing the central role. Users are able to access data (e.g. on Google Maps), rework it through another application to collaboratively create new content referred to as mash-ups. The original data are accessed through publicly available API's and redistributed in a new context unforeseen by the original "owners." On the Programmableweb.com web site, approximately three new mashups are listed each day, the majority related to mapping, photos, search, or video production. An example from Terra IMS (Internet Mapping Solutions) is a recently published map of United States Environmental Protection Agency Superfund pollution sites in the state of Florida. Drawing on data from Google Maps and a GeoIQ API from Fortiusone for geospatial analysis, the map dynamically plots location and information on the heavily polluted sites. In effect, the map does not exist in itself, but is dynamically compiled when requested by users from multiple data sources (www.terraims.com/gallery.php).

While mashups such as the example above require some technical knowledge of API's and Java, a wave of recent developments are simplifying the process for the end-user. This month the National Basketball Association (NBA) in the USA released the "highlight mixer tool," a set of tools for sports fans that draws upon a regularly updated database of NBA clips, team logos and music for sports fans to create their own personal highlight videos that can be posted back to the NBA web site or hosted at another location (http://myvideo.nba.com/). The videos require no media editing software as they are created directly on the site and can be put together in less than five minutes (Havenstein, 2007a). In early February, Yahoo! launched a new web site called Pipes, which essentially allow users to drag and drop data sources without knowledge of java. Tim O'Reilly spoke of this development as a "milestone in the history of the Internet." (Havenstein, 2007b) Perhaps that was the case since by the end of the first day Yahoo!, no stranger to significant web traffic, was forced to temporarily close the site due to the extensive demand. An example of a mashup, or "Pipe" for Yahoo!, is the "Apartment Near Something" site, which draws on multiple data sources including the Yahoo! search engine and apartment listings from Craigslist to create a new feed displaying rental units near any particular business or urban feature (Perez, 2007).

With the rapid proliferation of these easy-to-use publication and media creation and appropriate tools, traditional content providers including television, newspapers magazines are finding themselves forced to offer new services and reinvent their mission. End-users are rapidly gaining access to content in databases once off-limits to them and exercising new powers of content creation, editorial control and distribution. The web itself is becoming a vast electronic marketplace (perhaps in the sense of the Ancient Greek agora) for the exchange of ideas, experiences, and goods where content creation is in the hands of the many and not the few. This broader movement has been referred to as "social computing" where the primary function of software is to establish 
CWIS

24,3 a platform for interaction and community building. The results are already deeply ingrained in higher education, perhaps more than most faculty even realize. In the USA and other countries, the startling growth of massive online communities (MySpace and Facebook) is shifting the dynamics of the social environment in the once stable settings of college life.

A paradigm shift and the LCMS

While some of the Web 2.0 tools discussed in the contemporary media may represent passing fads, the disruptive effect of these applications will leave an enduring legacy. With AJAX, APIs, and other innovations, users are empowered in a radically decentralized environment. Publicly accessible APIs combined with the open-source movement offer opportunities to write new applications for data on remote application servers, shifting both the source of innovation and the control of data to the end-user. Even the data produced by individual users, such as bookmark lists, become "social" as users tag, aggregate and publish their bookmarks in loosely joined but powerfully effective collaborative endeavors such as del.ci.ous and other sites. Content is no longer "owned" but processed, no longer pushed out to a passive recipient, but appropriated and shared. According to Hinchcliffe (2006b), this new architecture of the web is marked by three fundamental paradigm shifts:

(1) A new process of innovation that moves from a top-down to a bottom-up model.

(2) A shift in the locus of value from the ownership of data to the end-user's experience and redistribution of data.

(3) The emergence of new online social structures in which power is located not in institutions but in communities.

Some evidence of these paradigm shifts is already evident in the experience of a new generation of students entering higher education. The development of applications that provide easy-to-use templates to create personal web spaces means that half of all teens in the USA may be considered "content creators" according to a recent Pew (2005) study. As Farmer (2006) argues, a generation is coming of age where the LCMS may seem as out of date as the traditional pre-web lecture classroom:

While Blackboard and WebCT claim to provide "cutting edge" technologies that "expand the boundaries of teaching and learning", the tools they actually provide are arguably as far removed from organic and developing online communication technologies as contemporary schools are removed from nineteenth century models and practice.

The question then is can the traditional LCMS model address the learning needs of future students who have not experienced the web as a delivery vehicle for pre-determined content but as a creative publication platform? From a broader perspective, the novelty of "anyway, anytime" access to academic resources (which still enthralls an older generation of faculty) is being replaced by the more radical perspectives of community-based appropriation, editing and self-publication.

In response to this, there are a number of projects to incorporate Web 2.0 elements into the LMCS model. Constructivist learning theory argues that knowledge is actively "constructed" through the learning process and that there is a continual process of adaptation based on the learner's experience (von Glaserfeld, 1984). The new user-centered tools and services such as blogs, wikis, and social bookmarking foster 
experience-based learning through tagging, AJAX-based projects, distributed conversations and collaborative writing. With the flexible nature of Web 2.0 services, it is becoming easier for faculty to create scenarios and case studies to foster problem-based learning where students are challenged to thinking critically and analytically and identify resources to resolve actual world problems. (See the University of Delaware PBL site: www.udel.edu/pbl/)

\section{Serving too many needs?}

A significant challenge for the traditional LCMS model is the institutional need to support a learning environment. It must "manage" and formalize the structure of this environment by offering user access management tools, attendance records, archiving capabilities, and ways of establishing and measuring outcomes. One effort to compare Web 2.0 services with VLEs has been undertaken by the Scottish Qualifications Authority (SQA), a non-departmental public body sponsored by the Scottish Executive Education Department which is responsible for accreditation, assessment and certification of non-degree qualifications. Though they do not address the underlying dynamics of these issues, they offer an insightful comparison of Web 2.0 developments in contrast to VLEs (Elliot, 2007). VLEs offer a consistent user experience, the same tools to all users, and provide faculty with greater control over the learning process. On the other hand, Web 2.0 applications offer a variety of rapidly improving services, tools that users are already familiar with, and offer individual resources that are better than their counterparts in VLEs. Elliot (2007) argues, "The main advantage of a VLE is its greatest weakness - the consistency of user experience. Whatever a learner does within a VLE, the look-and-feel will be similar. This consistency is comfortable for learners and (especially) teachers (who only need to learn one system) - but bland for learners since each tool will be inferior to an equivalent Web 2.0 offering."

Katz (2003) argues that the current structure of our LMS serves a variety of stakeholders and is caught between tradition and innovation, meeting institutional needs while simultaneously serving as the primary vehicle for the integration of technology in the learning environment. Unlike applications borne out of the needs of emerging communities (del.ci.ous itself has spawned a variety of social bookmarking applications), it does not have the flexibility to be quickly rewritten to serve user needs. If there is a single fundamental question that Web 2.0 poses for the traditional LMS in the academic community, it is the appropriateness of using enterprise software to serve as a top-down distribution vehicle for academic resources while simultaneously providing the digital space to foster innovation and collaboration from below. The larger issues this entails - including digital rights management and the tradition-bound rigid timeframes of academic work (which often limit the lifespan of emerging learning communities to a single semester) also come into play here.

\section{Digital copying and cloning}

Unlike so many of the instructional technology tools available in the teaching-learning environment, Yahoo!'s Pipes are remarkably easy to use, with nearly self-explanatory development features and a drag and drop interface. Two inconspicuous elements on the Pipes web sites point out the profound schism between the underlying paradigm of Web 2.0 activities and the current environment in higher education. First, the Yahoo! sites include a diagram of the user's mashup with the capability to edit the 
CWIS

24,3

158 organization of the clearly visible data feeds to create a new Pipe. Second, positioned on the menu bar spanning the top of the page is a "Clone" button to "grab" the data feeds for the user's own use. These features demonstrate the fundamental mindset of this emerging technology environment, that the tools and services that empower users are not "owned" but designed to be shared with others. Within higher education, one might argue that the stakes are fundamentally different than for the average user on the web. E-learning tools and resources are often developed by instructional designers, but just as often through the work of individual faculty. These accomplishments within the traditional framework of our institutional structures also play other roles, serving as the basis for promotion or other professional benefits in a faculty member's career. In our current academic environment, there are still fewer rewards for sharing resources than for pursuing the returns from a still lingering print publication paradigm (an issue deeply complicated by the unresolved state of digital rights management issues). On the other hand, one of the primary ways to achieve success in the fluid, unstructured environment of the web is to produce tools, services and content that are appropriated by others. The gift economy of the open-source movement is infectious here, and its absence in the academic environment is highlighted by the prohibition on digital copying, editing and cloning of the work of one's colleagues. Just try to imagine your current LCMS with a clone button the top of every online course site or learning object repository.

\section{Practical considerations}

While a significant transformation of our learning environments has been underway for over a decade with faculty rethinking and redesigning their teaching, the implications in the shift toward a highly participatory, user-centered web argues for a reconsideration of our current approach to the integration of technology into the teaching-learning paradigm. Many of our current strategies are effective, and it is critical that we continue to provide opportunities for training, instructional resource centers, effective communication with faculty and broad support from administrative areas. But as organizations themselves - including higher education institutions operate in a new, radically fluid environment characterized by media convergence, expectations for participation and a shift toward collective intelligence, the following may serve as useful ways of addressing the challenges we confront:

(1) Up to now, the institutional dialogue on the integration of technology into the learning environment has largely evolved, with good reason, within boundaries marked out by faculty with the additional participation of instructional technologists and course designers. But with the rapid evolution of a user-centered web that shifts the expectations of user participation in all areas of society, it is critical that institutions initiate a broader conversation on their organizational structure and the way they will operate in an increasingly decentralized landscape. With the average web user having access to publication tools and a potential audience that would have been the envy of any newspaper baron, higher education will have to rethink how it addresses the new communication paradigm.

At the College of New Rochelle, we are beginning to undertake this dialogue through presentations to a wide range of stakeholders, including the Board of 
Trustees, the President's team, and faculty and administrators. We are reflecting on a broad range of questions, including the following:

- What are the most effective avenues of communication within a shifting publication paradigm?

- How do we strike a balance between the coherence of our mission and the potential fragmentation of our learning and social community?

- How do we engage an increasingly tech-savvy generation of students? How do they understand the concept of community?

- These issues extend far beyond the specific questions of an LCMS in the learning environment, yet the issues are closely related.

(2) As the complexities of social networking within the broader social environment spillover into the institution, it is important that faculty achieve an acceptable comfort level with Web 2.0 applications and developments. Where in the past, it was sufficient to provide in-service workshops to train faculty in the use of an LCMS, new modes of faculty training will need to be designed. An example of a creative approach is that taken by Helene Blowers, technology director for the Public Library of Charlotte and Mecklenburg County in the USA. Used by a number of libraries from Virginia to Melbourne, Australia under a Creative Commons license, Learning 2.0 is an online project designed with Web 2.0 tools where library staff must complete $23 \mathrm{Web} 2.0$ related tasks. While the staff may not gain the full sense of the underlying mindset at stake in social networking, they will at least have a basic familiarity with these tools. However, it is remarkable that a single program designed at one institution suddenly emerges to have a global presence at a wide range of libraries.

(3) While there is no shortage of writing on constructivist learning theory, faculty will need to act upon their own ideas about the process of learning. As the modalities of communication shift the center of gravity toward the user, faculty roles will be challenged at an ever-quickening pace, demanding reflection on the learning process. An example of this is the current online discussion initiated by faculty at UCLA in response to the impact of podcasting on class attendance. In some large lecture courses, podcasts and RSS feeds are resulting in rows of empty seats, driving faculty to reconsider the purpose of face-to-face contact and characteristics of effective instruction.

(4) Currently, faculty (and others involved in instructional support) continue to play a largely passive role in the underlying design of our MLEs. In the previous decade, some faculty were deeply engaged in the design of instructional technology but largely withdrew as LCMS moved toward enterprise-level applications. But the wealth of new, user-friendly, tools in the Web 2.0 environment suggests that the all-in-one monolithic elearning systems may be entering a phase of obsolescence by the ongoing development of the web. As Morrison (2004) has argued, it is conceivable that "Learning objects and services could be and some might argue, should be, separated from the vehicle(s) which mediate their delivery. Designing an underlying architecture that would separate the delivery platform from the resources and services it provides would encourage even non-technically inclined faculty to take a more 
CWIS

24,3

proactive role as designers. There is something askew when sports fans can create a video in five minutes but faculty are required to spend hours to create their own media resources.

Each of these suggestions - institutional dialogue, new modalities of online training, faculty as reflective learners and rethinking the architecture of our LCMS are of course very different from earlier, workshop-based efforts to enhance faculty technology skills. But as the challenges are different, so will our solutions need to change. As the web itself rapidly evolves, it will be essential that faculty and instructional designers appropriate not only the tools of Web 2.0 services, but more importantly, an open, collaborative approach to reshaping the nature of our e-learning environments.

\section{Conclusion}

Perhaps the one surety we have in this transitional phase is that the LCMS of the future will offer a very different set of features and tools. The recent merger of BlackBoard and WebCT, the ongoing development of SAKAI and other open-source products, which offer the promise of easily shared learning tools, and new techniques such as AJAX, will drive the change process. Eventually, a generation of students will demand a more responsive set of learning tools. Just as they are quickly moving beyond the traditional institutional environment to create their own virtual social realms, they may one day create and utilize their own learning tools and communities. Of course, institutions will always hold the upper hand in these developments as they maintain the formal credentials students require for future careers. But this exercise of power is an illusion in a rapidly changing society and we want to engage our students through experiences that are both empowering and transformative. Doing this will require that we rethink our LCMS model, and grasp the reality that the underlying paradigms are, indeed, changing faster than we think.

\section{References}

Acker, S. (2004), "CMS and ePortfolio: at the crossroads", Campus Technology, September 27, available at: www.campustechnology.com/news_article.asp?id=10041\&typeid=155

Alexander, B. (2006), "Web 2.0: a new wave of innovation for teaching and learning?", EDUCAUSE Review, Vol. 41 No. 2, pp. 32-44.

Elliot, B. (2007), "E-assessment: what is Web 2.0?", available at: www.sqa.org.uk/sqa/22941.html

Farmer, J. (2006), "When digital dodos meet digital natives: the emerging redemption of online education", forthcoming conference on Internet Research 7.0: Internet Convergences, Brisbane, Australia, available at: http://conferences.aoir.org/viewabstract.php?id= $526 \& c f=5$

Harrington, C., Gordon, S. and Schibik, T. (2004), "Course management system utilization and implications for practice: a national survey of department chairpersons", Online Journal of Distance Learning Administration, Vol. 7 No. 4, available at: www.westga.edu/ distance/ ojdla/winter74/harrington74.htm

Havenstein, H. (2007a), "Create your own NBA highlight reels”, ComputerWorld: Networking and Internet, available at: www.macworld.com/news/2007/02/22/nba/index.php?lsrc=mwrss

Havenstein, H. (2007b), "Yahoo's pipes get clogged”, ComputerWorld: Development, available at: www.computerworld.com/action/article.do?command=viewArticleBasic\&articleId= 9010938 
Hinchcliffe, D. (2006a), “The Web 2.0 trinity: people, data, and great software”, blog entry, April 13, available at: http://web2.sys-con.com/read/207121.htm

Hinchcliffe, D. (2006b), “The shift to social computing”, blog entry, March 12, available at: http:// blogs.zdnet.com/Hinchcliffe/index.php?p=21

Katz, R. (2003), "Balancing technology and tradition: the example of course management systems", EDUCAUSE Review, Vol. 38 No. 4, pp. 50-9.

Morrison, D. (2004), "E-learning flexible frameworks and tools: is it too late? - the Director's Cut", ALT-C: University of Exeter, September, available at: www.bath.ac.uk/e-learning/ Download/DM20040909.pdf

O'Reilly, T. (2005), "What is Web 2.0? Design patterns and business models for the next generation of software", available at: www.oreillynet.com/pub/a/oreilly/tim/news/2005/09/ 30/what-is-web-20.html

Perez, J.C. (2007), "Yahoo tests RSS mashup creator for the masses", Computer World: Networking and Internet, available at: www.computerworld.com/action/article. do? command = viewArticleBasic\&articleId $=9010898 \&$ intsrc $=$ it_blogwatch

Pew (2005), "Teen content creators and consumers", November 2, available at: www.pewinternet. org/pdfs/PIP_Teens_Content_Creation.pdf

Reeves, T.C., Herrington, J. and Oliver, R. (2004), “A development research agenda for online collaborative learning”, Educational Technology Research and Development, Vol. 52 No. 4, pp. 53-66.

Sausner, R. (2005), “Course management: ready for prime time”, University Business, Vol. 8 No. 5 , available at: www.universitybusiness.com/page.cfm? $\mathrm{p}=791$

von Glasersfeld, E. (1984), “An introduction to radical constructivism”, in Watzlawick, P. (Ed.), The Invented Reality, W.W. Naughton \& Co., London.

\section{Further reading}

Feldstein, M. and Masson, E. (n.d.), "Unbolting the chairs: making learning management systems more flexible", E-learn Magazine (tutorial), available at: www.elearnmag.org/subpage. $\mathrm{cfm}$ ?section $=$ tutorials\&article $=22-1$

\section{Corresponding author}

Emory M. Craig can be contacted at: ecraig@cnr.edu

\footnotetext{
To purchase reprints of this article please e-mail: reprints@emeraldinsight.com
} Or visit our web site for further details: www.emeraldinsight.com/reprints 